\title{
Supply Curves for \\ Eco-efficient Environmental \\ Improvements Using \\ Different Weighting Methods
}

Evert Nieuwlaar, Geert Warringa, Corjan Brink, and

Walter Vermeulen

\section{Keywords}

atmospheric emissions

corporate environmental strategy

eco-efficiency

emission reduction

environmental prioritization

oil and gas producing industry

\author{
Address correspondence to: \\ Evert Nieuwlaar \\ Department of Science, Technology and \\ Society \\ Copernicus Institute \\ Utrecht University \\ P.O. Box 80.115 \\ 3508 TC Utrecht, The Netherlands \\ $<$ E.Nieuwlaar@chem.uu.nl> \\ $<$ www.copernicus.uu.nl>
}

I

\section{Summary}

Eco-efficiency implies environmental improvement at the lowest possible cost. When several environmental measures are possible, these can be ranked according to their cost per unit of environmental improvement, after which an eco-efficient set of measures can be selected that yields a given level of environmental improvement at least cost. This procedure can be visualized as a supply curve for environmental improvement. Such a curve plots cumulative cost or cost per unit of environmental improvement against cumulative environmental improvement, with measures ordered according to increasing cost per unit of environmental improvement. This paper presents supply curves for environmental improvement on the basis of a set of possible environmental measures for a company in the Dutch oil and gas producing industry.

To measure aggregated potential environmental improvement for a given measure, different environmental impacts are lumped together using weighting factors. We compare five methods for weighting environmental impacts, covering a wide range of current practices.

The supply curves that were determined for each of the five weighting methods show relatively small differences, except for one (the distance-to-target method). The ranking of measures differs significantly, though, and as a result, so do the measures that are selected if total costs are restricted to a certain budget. Also, the consequent reduction in emissions of specific substances, in particular nitrogen oxides $\left(\mathrm{NO}_{x}\right)$, depends on the weighting method selected. 


\section{Introduction}

The selection of measures for environmental improvement out of a large number of possibilities can be directed using economical (cost minimization) and ecological (maximization of environmental improvement) criteria. Eco-efficient selection can be achieved by selecting the measures that have the lowest cost per unit of environmental improvement-defined as the cost of the measure divided by the environmental improvement that would result from its implementation. To achieve this, environmental measures are first ranked according to their cost per unit of environmental improvement. Next, an eco-efficient set of measures is selected that either yields a given level of environmental improvement at least cost or yields the highest environmental quality at a given budget. This prioritization can be visualized as a supply curve for environmental improvement. Such a curve shows cumulative cost or cost per unit of environmental improvement against cumulative environmental improvement, with measures ordered according to increasing cost per unit of environmental improvement. Decision making on the set of measures to be implemented can then be based on either a budget or an upper limit to the cost per unit of environmental improvement. This paper presents supply curves for a set of possible environmental measures for a company in the Dutch oil and gas producing industry.

When measures involve the reduction of emission of a single substance, environmental improvement can be quantified easily as the (cumulative) emission reduction. The measures in our case study, however, involve the reduction of emissions to the atmosphere of various substances that can lead to various environmental impacts. Consequently, the environmental improvement brought about by the measures cannot be compared by looking only at emission reductions for each of the substances separately. To be able to compare environmental measures with respect to their environmental impacts, it is necessary to have a single value for the environmental improvement accomplished by each measure. This requires assigning a weight to each of the various substances that are affected. Several methods are available for weighting environmental im- pacts. A set of substance weighting factors for use by the Dutch oil and gas producing industry can be derived from the results of a study performed specifically for the Netherlands Oil and Gas Producers Association (NOGEPA), where a panel assigned weighting factors to environmental themes (Huppes et al. 2003). It is also possible to consider weighting factors that are based upon other procedures for weighting. The question to what extent the prioritization of environmental measures depends upon the weighting method selected as well as the weighting factors evolving from the selected weighting method can then be raised.

Several publications already exist in which comparisons have been made between existing weighting methods (Finnveden 1999; Guinée 2002; Dreyer et al. 2003). The results show significant differences in weighting factors for substances and environmental impact categories. The objective of this research, however, is to find out, in the case of atmospheric emissions by the oil and gas producing industry, to what extent the prioritization of environmental measures based upon eco-efficiency is influenced by the selection of weighting methods. Accordingly, the combined effect of weighting factors, magnitude of emission reductions, and emission reduction cost will be investigated.

To investigate the influence of the selected weighting method on the selection of environmental measures in the oil and gas producing industry, we will select a number of alternative weighting methods, derive associated weighting factors, and construct supply curves using each of the selected weighting methods. Differences in the mix of selected measures at a given budget will be investigated.

This approach is general enough to be applicable to cases other than the oil and gas producing industry. The applicability of the results of this research is, however, limited by the nature of the case: atmospheric emissions by the oil and gas producing industry. This means that environmental impacts caused by environmental interventions other than atmospheric emissions (e.g., emissions to water and soil, changes in land use) are not included. In addition, because the result of weighting implies weighting factors and magnitude of emissions, the representativeness of 
the results is limited to cases that are similar to the oil and gas producing industry.

\section{Data}

Data were obtained from a Dutch company in the oil and gas production industry (Nederlandse Aardolie Maatschappij, NAM) for the 70 possible environmental measures listed in their second company environmental plan for reducing atmospheric emissions (NAM 2000). The data include capital and operating costs/revenues, lifetimes of the measures, and annual emission reductions. Emission reductions data for the following substances were provided: carbon dioxide $\left(\mathrm{CO}_{2}\right)$, carbon monoxide $(\mathrm{CO})$, nitrogen oxides $\left(\mathrm{NO}_{x}\right)$, sulfur dioxide $\left(\mathrm{SO}_{2}\right)$, methane $\left(\mathrm{CH}_{4}\right)$, ethane $\left(\mathrm{C}_{2} \mathrm{H}_{6}\right)$, BTEX (= benzene, toluene, ethylbenzene, xylene), VOC (volatile organic compounds, not including BTEX, $\mathrm{CH}_{4}$, and ethane), benzene (when not included in BTEX), mercury $(\mathrm{Hg})$, and the fluorocarbons HCFC-22 and Halon 1301. The BTEX emission is subdivided into onshore and offshore emissions, but for reasons explained later, this distinction is ignored.

For some substances only a few reduction measures are available within the set of measures: only one for HCFC-22, one for Halon 1301, three for sulfur dioxide, and two for mercury. Most of the measures reduce emissions of more than one of the mentioned substances. Examples of measures are the adaptation of cooling equipment to reduce leakages of HCFC-22, the reduction of $\mathrm{NO}_{x}$ emissions by modification and motor management, flare modifications, and minimization of vent emissions.

\section{Selection of Weighting Methods}

We will use different weighting methods to calculate the environmental improvement for each measure. The selection of weighting methods covers a wide range of current practices.

Various methods have been developed for weighting emissions. They can be divided into several categories. We follow the classification developed by Lindeijer (1996), based upon work by Hofstetter (1998), which leaves out proxy methods (such as energy requirements) for their lack of intereffect weighting, as well as technology methods (such as the ecological footprint) for their data gaps (Finnveden 1999). This classification distinguishes panel methods, monetization methods, and methods based on policy targets.

In panel methods respondents are asked to give weights to impact categories (such as climate change or acidification) or to damage categories (such as human health damage or ecosystem damage). An important distinction is at what point in the chain from emissions to environmental impact the weights are given. In the first case weights are given at an intermediate point in the chain of environmental processes leading to environmental damage; this is referred to as problem-oriented or midpoint weighting. The second case is referred to as damage-oriented or endpoint weighting. The panel can consist of experts, stakeholders, and/or laypeople.

Monetization methods share the feature that weighting is based on and/or expressed in monetary cost or value; this can be on individuals' or society's willingness to pay, or otherwise-for instance, the cost of remediation.

Policy-target-based methods are methods where policy targets determine what weighting factors are used. Policy targets can be based on intermediately attainable levels, long-term sustainable emission levels, or no-effect levels.

We have selected the following five weighting methods, covering the three categories mentioned:

\section{CMLINOGEPA (abbreviated NOGEPA)}

This is the method developed by the Leiden University Institute of Environmental Sciences (CML) specifically for the Netherlands Oil and Gas Producers Association (NOGEPA) (Huppes et al. 2003). It is based on midpoint weighting by a panel of stakeholders (from government and industry) as well as experts. We will use this method as a reference and compare it with the other weighting methods.

\section{Eco-indicator 99 (abbreviated ECO99)}

This method is based on endpoint panel weighting, for which the panel consisted of a Swiss life-cycle assessment interest group (Goedkoop and Spriensma 2001). 


\section{Environmental Priority Strategies 2000 (abbreviated EPS)}

This is a monetization method in which weighting is based on willingness to pay to undo impacts (Steen 1999a).

\section{CE Method (abbreviated CE)'}

This is actually a mix of monetization and policy targets. The weighting factor is the marginal prevention cost to meet the Dutch governmental target (Wit et al. 1997; Davidson et al. 2002).

\section{Distance to Target (abbreviated DTT)}

In this method, weighting for each substance is based on the difference between the actual emission level and the emission policy target of the substance.

\section{Weighting Factors}

We will now derive, for each of the selected weighting methods, the weighting factors for the substances that are affected by the set of emission reduction measures considered in the analysis. The procedure for obtaining the weighting factors differs for each weighting method. Because the composition of the aromatics in the BTEX emission reductions is not known and separate factors for all constituents of BTEX cannot be obtained for each weighting method, it was decided to treat all BTEX as benzene.

\section{NOGEPA}

Weighting is done at the midpoint level. Weighting factors are calculated by the formula:

$$
w_{i}=\sum_{t} \frac{K_{i, t}}{N_{t}} * W_{t}
$$

where $w_{i}$ is the weighting factor for substance $i$; $K_{i, t}$ is the characterization factor for substance $i$ and environmental theme $t$; $N_{t}$ is the normalization factor for environmental theme $t$; and $W_{t}$ is the weighting factor for environmental theme $t$.

The environmental themes included are climate change, ozone layer depletion, photochemical oxidant creation, acidification, eutrophica-
Table I Weighting factors for environmental themes in the NOGEPA method

\begin{tabular}{lc}
\hline Environmental theme & Weight \\
\hline Climate change & 32 \\
Ozone layer depletion & 5 \\
Photochemical oxidation & 8 \\
Acidification & 6 \\
Eutrophication & 13 \\
Human toxicity & 16 \\
Fresh water eco-toxicity & 6 \\
Marine eco-toxicity & 8 \\
Terrestrial eco-toxicity & 5 \\
Total & 99 \\
\hline
\end{tabular}

tion, human toxicity, fresh water eco-toxicity, marine eco-toxicity, and terrestrial eco-toxicity. The characterization factors $K_{i, t}$ are obtained from recommended methods and data from the CML handbook (Guinée 2002). These were normalized using the emission data for the Netherlands in 1997 obtained from the same publication. For VOC a characterization factor of 0.35 kilograms of ethylene equivalents per kilogram $\left(\mathrm{kg} \mathrm{C} \mathrm{C}_{2} \mathrm{H}_{4}\right.$-eq $\left./ \mathrm{kg}\right)$ was chosen for its photochemical oxidant creation potential. ${ }^{2} \mathrm{NO}_{x}$ is treated as $\mathrm{NO}_{2}$ in all cases, which is a worstcase approach for photochemical oxidant creation, because NO has a negative characterization factor whereas this factor is positive for $\mathrm{NO}_{2}$. Finally, the weighting factors $\left(W_{t}\right)$ for the environmental themes were taken from work by Huppes and colleagues (2003), who describe the outcome of consulting a panel of stakeholders and experts specifically for the NOGEPA (table 1).

\section{Eco-indicator 99}

Weighting factors for all substances were taken from work by Goedkoop and Spriensma (2001). Damage modeling and weighting in this method vary with the cultural perspective selected (individualist, hierarchic, or egalitarian). In addition, a selection is to be made as to whether weighting was the average over the whole panel. Here the default hierarchic version with average weighting factors was chosen (Goedkoop and Spriensma 2001). 


\section{EPS}

Weighting factors for all substances were taken directly from an article by Steen (1999b). These are reported in the form of environmental load units (ELU) per kg of emission, so no further calculations were required.

\section{CE}

For most of the substances, weighting factors could be determined on the basis of shadow prices that are published and documented by CE (Davidson et al. 2002). For some substances (ethane, benzene, and Halon 1301) the shadow prices were calculated by us, using the principles developed by CE.

\section{DTT}

The weighting factors used here are calculated using the Swiss ecoscarcity method (Ahbe et al. 1990; BUWAL 1998) with data for the Netherlands instead of Switzerland. Weighting factors for substances are calculated with the formula

$$
w_{i}=\frac{R_{i}}{T_{i}} * \frac{1}{T_{i}}
$$

where $w_{i}$ is the weighting factor for substance $i$; $R_{i}$ is the actual emission level in the Netherlands in 1998; and $T_{i}$ is the emission target in the Netherlands in 2010.

The weighting factor consists of a term normalizing emissions with respect to the target $\left(1 / T_{i}\right)$ and a term representing the distance-totarget factor $\left(R_{i} / T_{i}\right)$. Actual emissions in 1998 $\left(R_{i}\right)$ and target emissions $\left(T_{i}\right)$ for 2010 are included in table 2 .

The resulting weighting factors for the five selected methods are given in table 2 . To make comparisons between the different weighting methods possible, the weighting factors are scaled so that for each weighting method the weighting factor for $\mathrm{CO}_{2}$ equals 1.0. These scaled weighting factors are shown in table 3 .

Table 3 shows that there are large differences between the weighting methods and that these are the most extreme for the DTT method. In addition, the DTT method suffers from lacking data.

\section{Weighting Factors and Emissions}

The environmental improvement, EI, obtained by implementing environmental measures is calculated as

$$
\mathrm{EI}=\sum_{i} w_{i} E_{i}
$$

where $w_{i}$ is the weighting factor of substance $i$ and $E_{i}$ is the avoided emission of substance $i$.

This means that the environmental improvement depends on the weighting factors (table 3 ) as well as the magnitude of the avoided emissions $E_{i}$. The combined effect of weighting factors and emission magnitudes is shown in figure 1 for the five weighting methods with all 70 measures implemented.

Figure 1 shows the contribution of each substance to the environmental improvement obtained when all 70 measures in the oil and gas production company are implemented. Benzene is dominant in the DTT method and has a significant contribution in the CE method (as calculated by the authors). In the Eco-indicator 99 method NOx is the dominant substance. Methane makes a significant contribution in the EPS method, which is not caused by its weighting factor, but merely by the fact that the weighting factors for other substances are relatively low when compared with those for the other weighting methods (see table 3). Substances such as $\mathrm{CO}$, $\mathrm{SO}_{2}$, and HCFC-22 are of minor significance, which is mainly caused by the low magnitude of the emission reductions of these substances. The NOGEPA method shows no dominant substance.

\section{Supply Curves}

The concept of supply curves for environmental improvement is derived from similar concepts in the field of energy efficiency research. For example, the potential for energy efficiency and the associated $\mathrm{CO}_{2}$ emission reduction in the Netherlands has been presented using supply curves (Alsema and Nieuwlaar 2001). The importance and the usefulness of the concept have been discussed by several authors (Blumstein and Stoft 1995; Stoft 1995; Verdonck and 
Table 2 Weighting factors for substances for five weighting methods

\section{DTT}

\begin{tabular}{lccccccc}
\cline { 6 - 8 } & $\begin{array}{c}\text { NOGEPA } \\
\left(\mathrm{kg}^{-1}\right)\end{array}$ & $\begin{array}{c}\text { ECO99 } \\
(\text { points })\end{array}$ & $\begin{array}{c}\text { EPS } \\
(\text { ELU } / \mathrm{kg})\end{array}$ & $\begin{array}{c}\mathrm{CE} \\
(€ / \mathrm{kg})\end{array}$ & $\begin{array}{c}\text { Emissions 1998 } \\
(\text { tons })\end{array}$ & $\begin{array}{c}\text { Target 2010 } \\
(\text { tons })\end{array}$ & $\begin{array}{c}\text { Weighting } \\
\text { factor }\left(\mathrm{kg}^{-1}\right)\end{array}$ \\
\hline $\mathrm{CO}_{2}$ & $1.29 \times 10^{-12}$ & 0.0055 & 0.108 & 0.05 & $1.86 \times 10^{8}$ & $1.27 \times 10^{8 a}$ & $1.15 \times 10^{-8}$ \\
$\mathrm{CH}_{4}$ & $2.97 \times 10^{-11}$ & 0.114 & 2.72 & 1.06 & $1.07 \times 10^{6}$ & $6.70 \times 10^{5 b}$ & $2.40 \times 10^{-6}$ \\
$\mathrm{CO}$ & $1.20 \times 10^{-11}$ & 0 & 0.331 & 0.07 & - & - & - \\
$\mathrm{NOx}$ & $9.17 \times 10^{-11}$ & 2.75 & 2.13 & 5.53 & $4.41 \times 10^{5}$ & $2.31 \times 10^{5}$ & $8.26 \times 10^{-6}$ \\
$\mathrm{SO}_{2}$ & $1.30 \times 10^{-10}$ & 1.53 & 3.27 & 4.80 & $1.13 \times 10^{5}$ & $4.60 \times 10^{4}$ & $5.32 \times 10^{-5}$ \\
Ethane & $5.45 \times 10^{-11}$ & 0.0069 & 1.46 & $0.26^{c}$ & - & - & $1.25 \times 10^{-5}$ \\
VOC & $1.55 \times 10^{-10}$ & 0.033 & 2.14 & 0.90 & $3.01 \times 10^{5}$ & $1.55 \times 10^{5}$ & $1.25 \times 10^{-5}$ \\
Benzene & $1.15 \times 10^{-10}$ & 0.073 & 3.65 & $9.67^{e}$ & 6471 & 2081 & $1.49 \times 10^{-3}$ \\
$\mathrm{Hg}$ & $7.82 \times 10^{-8}$ & 64.7 & 61.4 & 613 & 0.557 & 0.45 & 2.75 \\
$\mathrm{HCFC}-22$ & $3.95 \times 10^{-9}$ & 8.4 & 194 & 86.0 & - & - & - \\
Halon 1301 & $6.27 \times 10^{-7}$ & 143 & 2200 & $640^{f}$ & - & - & - \\
\hline
\end{tabular}

${ }^{a}$ Target emission, from (VROM 1997).

${ }^{b}$ Target emission, from (VROM 2001).

${ }^{c}$ Shadow price for ethane based upon photochemical oxidant creation: characterization factor 0.123 kilograms of $\mathrm{C}_{2} \mathrm{H}_{4}$ equivalents per kilogram $\left(\mathrm{kg} \mathrm{C}_{2} \mathrm{H}_{4}\right.$-eq $\left./ \mathrm{kg}\right)$ and shadow price for ethylene $€ 2.14 / \mathrm{kg} \mathrm{C}_{2} \mathrm{H}_{4}$-eq.

${ }^{d}$ For ethane, same DTT weighting as for VOC assumed.

e Shadow price for benzene based upon photochemical oxidant creation and human toxicity. For photochemical oxidant creation, characterization factor $0.22 \mathrm{~kg} \mathrm{C}_{2} \mathrm{H}_{4}$-eq $/ \mathrm{kg}$. For human toxicity, maximum tolerable concentration of $10 \mu \mathrm{g} / \mathrm{m}^{3}$ (RIVM 2001).

f Shadow price for Halon 1301 based upon climate change and ozone depletion. For climate change, characterization factor $5600 \mathrm{~kg} \mathrm{CO}$-eq $/ \mathrm{kg}$. For ozone depletion, characterization factor $12 \mathrm{~kg} \mathrm{HCFC}-11$-eq $/ \mathrm{kg}$, shadow price $€ 30 / \mathrm{kg}$ HCFC-11-eq.

Notes: NOGEPA = Netherlands Oil and Gas Producers Association; ECO99= Eco-indicator 99; EPS = Environmental Priority Strategies 2000; CE = an environmental consultancy organization located in Delft, The Netherlands; DTT = distance to target. $\mathrm{CO}_{2}=$ carbon dioxide; $\mathrm{CH}_{4}=$ methane; $\mathrm{CO}=$ carbon monoxide; $\mathrm{NO}_{x}=$ nitrogen oxides; $\mathrm{SO}_{2}=$ sulfur dioxide; $\mathrm{VOC}=$ volatile organic compounds; $\mathrm{Hg}=$ mercury. $\mathrm{ELU}=$ environmental load units; $€=$ Euros; $1 \mathrm{~kg}$ $(\mathrm{SI}) \approx 2.204 \mathrm{lb} ; 1$ ton $=1 \mathrm{Mg}(\mathrm{SI})=10^{3} \mathrm{~kg} \approx 1.102$ short tons. For the DTT method, the 1998 emissions (RIVM, 1999) and 2010 target emissions (RIVM 2003) are also given.

Table 3 Scaled weighting factors (weighting factor $\mathrm{CO}_{2}=1$ )

\begin{tabular}{lrrrrr}
\hline & NOGEPA & ECO99 & \multicolumn{1}{c}{ EPS } & \multicolumn{1}{c}{ CE } & \multicolumn{1}{c}{ DTT } \\
\hline $\mathrm{CO}_{2}$ & 1.0 & 1.0 & 1.0 & 1.0 & 1.0 \\
$\mathrm{CH}_{4}$ & 23.1 & 20.9 & 25.2 & 21.3 & 208.1 \\
$\mathrm{CO}$ & 9.3 & 0.0 & 3.1 & 1.3 & - \\
$\mathrm{NO}_{x}$ & 71.1 & 504.6 & 19.7 & 110.6 & 717.0 \\
$\mathrm{SO}_{2}$ & 100.8 & 280.7 & 30.3 & 96.0 & $4,621.9$ \\
Ethane & 42.3 & 1.3 & 13.5 & 5.3 & $1,088.5$ \\
VOC & 120.5 & 6.1 & 19.8 & 18.0 & $1,088.5$ \\
Benzene & 89.5 & 14.2 & 33.8 & 193.4 & $1.30 \times 10^{5}$ \\
Hg & $60,612.5$ & $11,871.6$ & 568.5 & $12,266.7$ & $2.39 \times 10^{8}$ \\
HCFC-22 & $3,062.5$ & $1,541.3$ & $1,796.3$ & $1,720.4$ & - \\
Halon 1301 & $486,496.5$ & $26,220.2$ & $20,370.4$ & $12,800.0$ & - \\
\hline
\end{tabular}

Note: NOGEPA = Netherlands Oil and Gas Producers Association; ECO99= Eco-indicator 99; EPS = Environmental Priority Strategies 2000; CE = an environmental consultancy organization located in Delft, The Netherlands; DTT $=$ distance to target. $\mathrm{CO}_{2}=$ carbon dioxide; $\mathrm{CH}_{4}=$ methane; $\mathrm{CO}=$ carbon monoxide; $\mathrm{NO}_{x}=$ nitrogen oxides; $\mathrm{SO}_{2}=$ sulfur dioxide; VOC $=$ volatile organic compounds; $\mathrm{Hg}=$ mercury. 


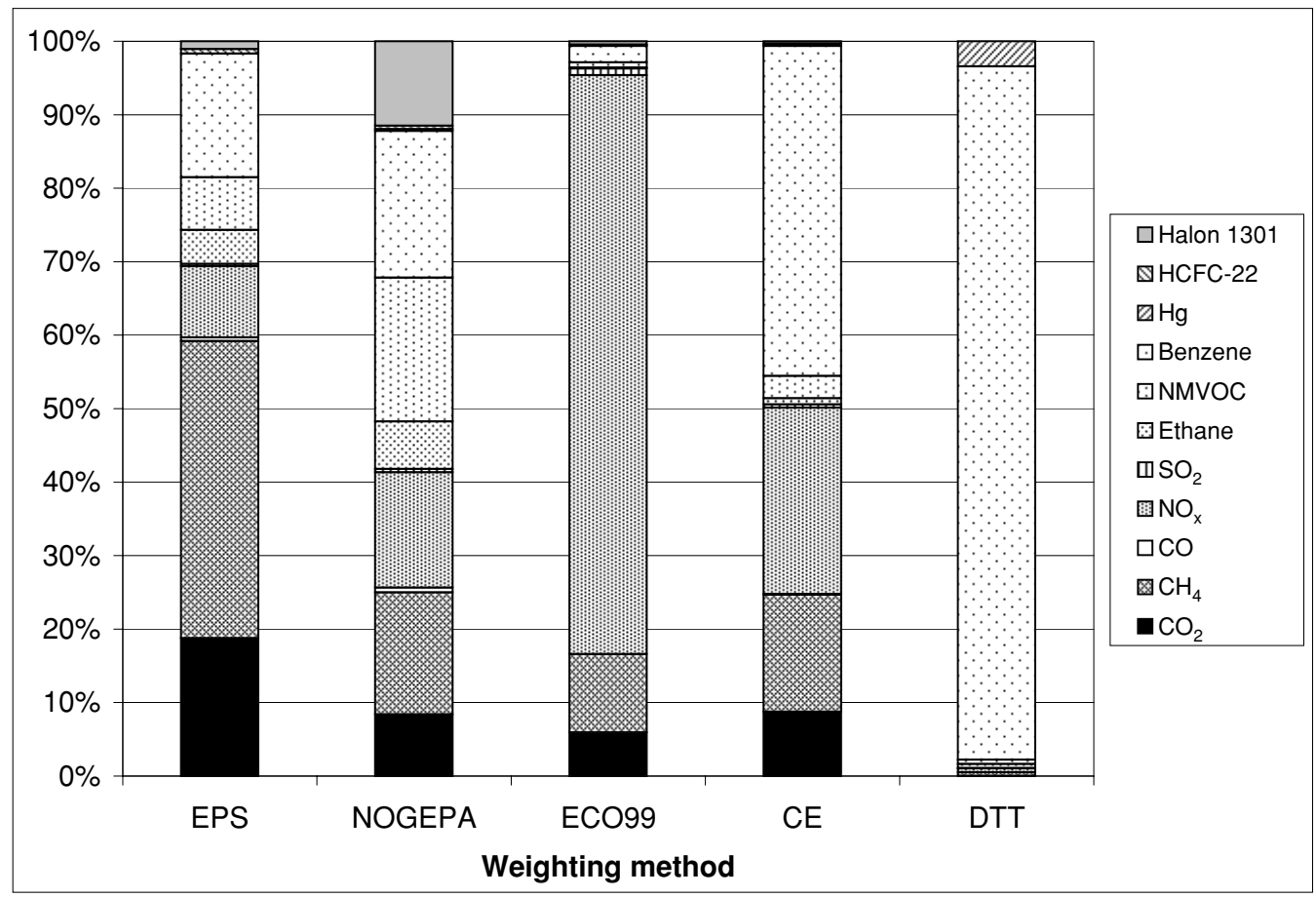

Figure I Contribution of each substance to the environmental improvement when all 70 measures are implemented. EPS = Environmental Priority Strategies 2000; NOGEPA = Netherlands Oil and Gas Producers Association; ECO99 = Eco-indicator 99; CE = an environmental consultancy organization located in Delft, The Netherlands; DTT = distance to target. $\mathrm{Hg}=$ mercury; NMVOC = nonmethane volatile organic compounds; $\mathrm{SO}_{2}=$ sulfur dioxide; $\mathrm{NO}_{x}=$ nitrogen oxides; $\mathrm{CO}=$ carbon monoxide; $\mathrm{CH}_{4}=$ methane; $\mathrm{CO}_{2}=$ carbon dioxide.

Verbruggen 1998; Willemé 2003). Energy conservation supply curves (CSC) are constructed by ranking measures according to increasing cost per unit of environmental improvement. The vertical axis shows marginal cost of energy conservation (in monetary units per unit energy saved) and the horizontal axis shows the cumulative amount of energy conserved annually. Another form in which the supply curve can be presented is the total cost of conserved energy curve (TCC). The difference from CSC is that the vertical axis in TCC represents the annual total cost of energy conservation.

Similar curves can be constructed for the supply of environmental improvement. For these curves, conserved energy in the CSC and TCC is replaced by a measurement of environmental improvement. The weighted sum of avoided emissions for each measure serves this purpose, where weighting takes place using the scaled weighting factors in table 3. We restrict ourselves to the presentation of the curves for total cost of supply of environmental improvement, referred to as environmental total cost curves (environmental TCC).

The cost per unit of environmental improvement for each of the 70 measures is calculated by dividing the annual cost of environmental improvement in 2006 by the environmental improvement in the year 2006. From the available data the annual costs pertaining to the year 2006 were calculated using a $10 \%$ discount rate and appropriate lifetimes of the measures. The environmental total cost curves are constructed under the (in this case verified) assumption that the measures can be taken independently, which means that the cost and the environmental improvement of a measure do not depend on the results of previous measures. When such dependencies would have existed, additional procedures 
are required to account for the dependencies, as demonstrated by various authors (e.g., Alsema and Nieuwlaar 2001; Willemé 2003).

Figure 2 shows the environmental TCC using the NOGEPA weighting method along with the environmental TCCs of the four other methods. On the vertical axis it shows, for each data point, the cumulative annual cost when measures are taken prioritized on eco-efficiency in terms of Euros per unit of environmental improvement (i.e., measures with the lowest cost per unit environmental improvement are taken first). The horizontal axis shows the cumulative environmental improvement. The axis has been scaled from 0 (no environmental improvement) to 1 (environmental improvement by taking all 70 measures).

For the NOGEPA method the first 11 measures are cost-effective, in the sense that they have negative or zero annual cost. This causes the cost curve to slope downward in the beginning. These measures account for $17 \%$ of

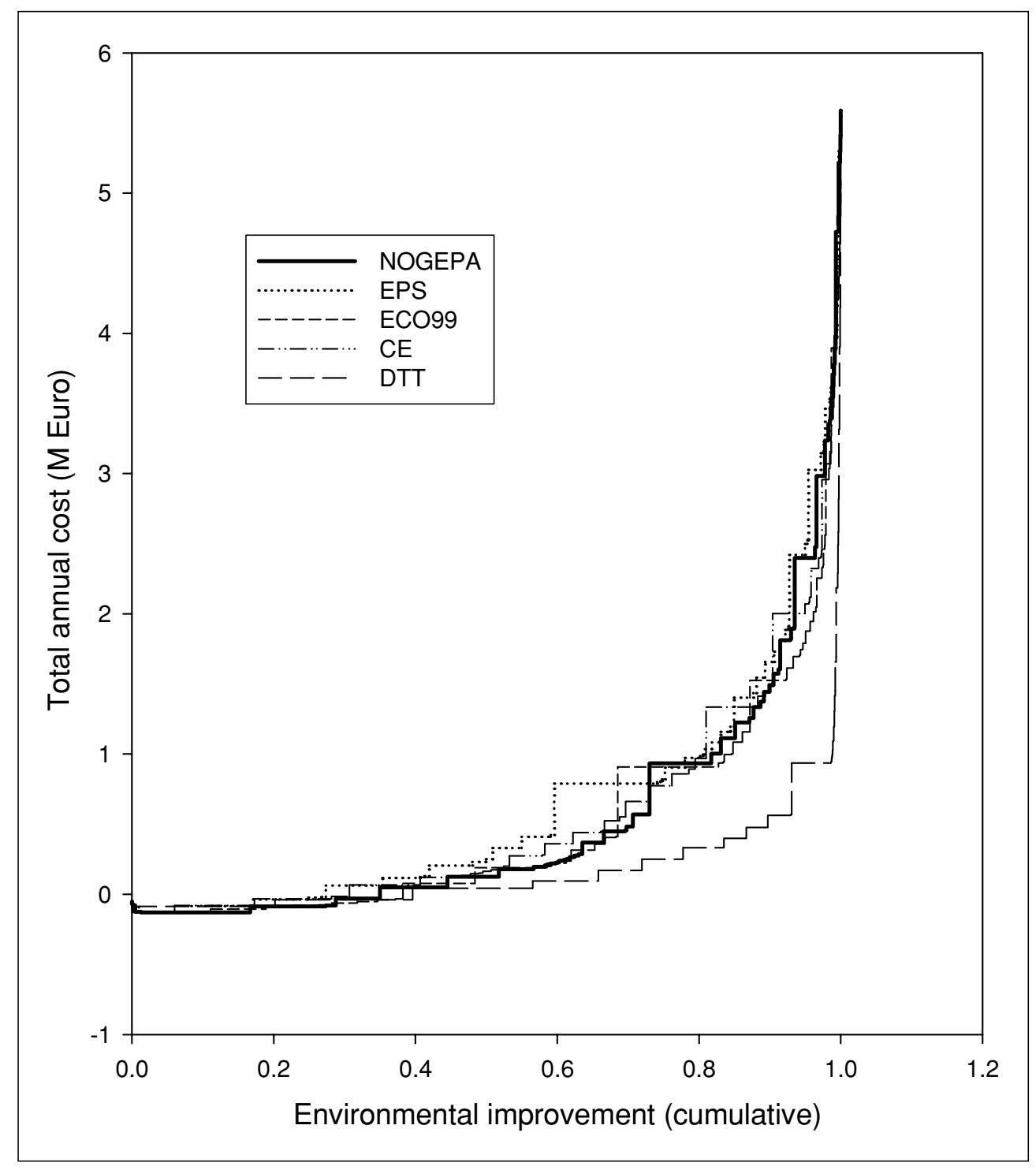

Figure 2 Environmental total cost curve with five weighting sets. M Euro = million Euro. 
environmental improvement. After these measures the TCC rises and becomes steeper with each following measure, reflecting the increasing cost per unit of environmental improvement. The TCC crosses the horizontal axis (zero total annual cost) at about $40 \%$ of attainable environmental improvement. Actually, $35 \%$ is attained (with 15 measures) before a measure is taken that would bring the company into the situation where it has positive total annual cost in taking environmental measures. The measures on the right-hand side of the curve (e.g., beyond $80 \%$ environmental improvement) represent the least eco-efficient measures, brought about by high cost and small environmental improvements. An annual cost of 5.6 million Euros $(\mathrm{M} €)$ is required for the implementation of all 70 measures together. Almost $95 \%$ would be obtained with an annual budget of $2 \mathrm{M} €$. In the following we will assume that measures exceeding an annual budget of $1 \mathrm{M} €$ are too expensive.

Except for the DTT method, the differences in the score for environmental improvement are not very large. At $1 \mathrm{M} €$ annual cost they range from 0.81 for the CE method to 0.85 for the Ecoindicator 99 method (see table 4). For the DTT method $99 \%$ of environmental improvement is obtained at the $1 \mathrm{M} €$ budget.

Although the total scores for environmental improvement do not differ much, the ranking of measures in the TCC depends more directly on the weighting method used. As a result, there are differences in the emission reductions of in- dividual substances when the $1 \mathrm{M} €$ budget limit is applied. The differences in the outcomes become clearer when a more detailed look is taken at the extent to which the various emissions are reduced. Table 4 shows the emission reductions of the key substances as a percentage of the total emission reduction for each substance when all 70 measures are taken.

It turns out that 22 out of the total of 70 available measures are selected in all cases when the $1 \mathrm{M} €$ budget limit is applied. These include the 11 cost-effective measures mentioned before (having zero or negative cost) as well as 5 lowcost $\mathrm{NO}_{x}$ emission-reducing measures. On the other hand, there are 25 measures that are never selected when the budget limit is applied. These measures include the only 2 measures for $\mathrm{SO}_{2}$ emission reduction, an expensive $\mathrm{NO}_{x}$ emission reduction measure, and 15 measures reducing emissions of carbon dioxide together with hydrocarbons $\left(\mathrm{CH}_{4}\right.$, ethane, VOC, BTEX).

These outcomes further show some differences depending on the weighting method chosen, which cannot be seen directly from the supply curves. We will treat these differences by pairwise comparing the NOGEPA method with the alternative methods.

\section{NOGEPA versus EPS}

The outcomes with the EPS methods and the NOGEPA method exhibit only a small difference. In fact, with one exception both methods

Table 4 Environmental improvement and emission reductions (calculated using five different weighting methods) for substances that are most greatly affected at an annual budget of $1 \mathrm{M} €$, as a fraction of the total obtainable improvement for each substance by implementing all 70 measures without regard to budget

\begin{tabular}{lccccc}
\hline & NOGEPA & EPS & ECO99 & CE & DTT \\
\hline Total obtainable improvement & $83 \%$ & $81 \%$ & $85 \%$ & $81 \%$ & $99 \%$ \\
$\mathrm{NO}_{x}$ & $48 \%$ & $46 \%$ & $98 \%$ & $75 \%$ & $35 \%$ \\
$\mathrm{CO}_{2}$ & $89 \%$ & $89 \%$ & $43 \%$ & $50 \%$ & $73 \%$ \\
$\mathrm{CH}_{4}$ & $77 \%$ & $77 \%$ & $29 \%$ & $64 \%$ & $76 \%$ \\
VOC & $92 \%$ & $92 \%$ & $39 \%$ & $86 \%$ & $93 \%$ \\
BTEX & $96 \%$ & $96 \%$ & $51 \%$ & $97 \%$ & $99 \%$ \\
\hline
\end{tabular}

Notes: NOGEPA = Netherlands Oil and Gas Producers Association; EPS = Environmental Priority Strategies 2000; ECO99 = Eco-indicator 99; $\mathrm{CE}=$ an environmental consultancy organization located in Delft, The Netherlands; $\mathrm{DTT}=$ distance to target. $\mathrm{NO}_{x}=$ nitrogen oxides; $\mathrm{CO}_{2}=$ carbon dioxide; $\mathrm{CH}_{4}=$ methane; VOC $=$ volatile organic compounds; BTEX = benzene, toluene, ethyl benzene, xylene. 
select the same measures within the $1 \mathrm{M} €$ budget. In the EPS method one $\mathrm{NO}_{x}$ emission-reducing measure is discarded.

\section{NOGEPA versus CE}

Compared with the NOGEPA-method, the CE method selects four mostly $\mathrm{NO}_{x}$ emissionreducing measures before one large project (0.36 M€ annual cost) involving a significant reduction in greenhouse gas emissions. At the $1 \mathrm{M} €$ budget limit this project just has become cost-effective, but when the budget limitation is strictly applied, this project is not selected, and its impact therefore is not shown in the results of table 4. If this measure had been included, the results would have been similar to the NOGEPA outcome, except for $\mathrm{NO}_{x}$.

\section{NOGEPA versus Eco-indicator 99}

The Eco-indicator 99 method shows a strong preference for $\mathrm{NO}_{x}$ emission-reducing measures. Compared with the measures selected when the NOGEPA method is used, the Eco-indicator 99 method selects five $\mathrm{NO}_{x}$ emission reduction measures at the cost of seven measures reducing greenhouse gas and VOC emissions.

\section{NOGEPA versus DTT}

Here the DTT method selects a VOC- and BTEX-reducing measure at the cost of six other measures that mostly reduce greenhouse gas and $\mathrm{NO}_{x}$ emissions.

\section{Discussion}

Supply curves in the form of environmental total cost curves can be used to determine maximum environmental improvement given a certain budget. Once a set of weighting factors is chosen, supply curves can also be constructed when environmental improvement measures affect the emissions of several substances. If, however, environmental management or policy requires certain targets to be reached for specific substances, the procedure does not guarantee that such targets will be met, let alone in the most cost-effective way. A more detailed analysis of underlying data and the construction of supply curves for specific substances may help in finding cost-effective strategies while fulfilling accepted targets for single substances.

In addition to the default NOGEPA method, four alternative weighting methods have been used to construct the supply curves for the oil and gas industry case. The Eco-indicator 99 method shows the largest differences from the NOGEPA method for all key substances shown in table 4 . This is in contrast to the total score, where the DTT method shows the largest difference from the NOGEPA method. This is caused by the extremely high weighting factors for VOC and, especially, BTEX in the DTT method and the fact that remaining options to reduce these emissions are relatively expensive.

The largest changes are found in the $\mathrm{NO}_{x}$ emission reduction brought about by the selected measures under the budget constraint. Every change from the NOGEPA method to one of the other methods leads to a change in selected measures such that $\mathrm{NO}_{x}$ emission reduction changes significantly, except for the EPS method. This is caused by either a relatively high weighting factor for $\mathrm{NO}_{x}$ itself (Eco-indicator 99 and CE method) or the much higher weighting factors for other substances (benzene in the DTT method).

In the DTT method no weighting factors could be derived for CO, HCFC-22, or Halon 1301. Their low emissions did not lead to high contributions to the results for the other weighting methods (as shown in figure 1). It is therefore likely that these missing data do not seriously affect the results.

\section{Conclusions}

Supply curves for environmental improvement are a useful tool for eco-efficient decisionmaking. In the form of environmental total cost curves these curves reflect the maximum environmental improvement that can be obtained with a certain budget. The use of a weighting method enables the analysis of eco-efficiency in situations where several environmental aspects have to be accounted for.

Except for the DTT method, no large differences are found in the supply curves constructed 
in the case study with data from the oil and gas producing industry using different weighting methods. Further analysis of the results, however, shows that except for the EPS method and to a lesser extent the CE method, significant changes can occur in the prioritization of environmental measures if other weighting methods are selected instead of the NOGEPA method. Consequently, the reduction in emissions of the various substances, in particular $\mathrm{NO}_{x}$, that results from the measures selected under a budget restriction depends on the weighting method selected.

\section{Notes}

1. $\mathrm{CE}$ is an environmental research and consultancy organization located in Delft, The Netherlands.

2. One $(\mathrm{kg}(\mathrm{SI}) \approx 2.204 \mathrm{lbs}$.

\section{References}

Ahbe, S., A. Braunschweig, and R. Müller-Wenk. 1990. Methodik für Oekobilanzen auf der Basis ökologischer Optimierung [A method for ecobalance and ecological optimization]. Bern: Bundesambt für Umwelt, Wald und Landschaft (BUWAL).

Alsema, E. A. and E. Nieuwlaar. 2001. ICARUS-4: A database of energy-efficiency measures for The Netherlands, 1995-2020. Final report. Utrecht: Utrecht University, Copernicus Institute: 55.

Blumstein, C. and S. E. Stoft. 1995. Technical efficiency, production functions and conservation supply curves. Energy Policy 23(9): 765-768.

BUWAL (Bundesamt für Umwelt, Wald und Landschaft). 1998. Ökobilanzen, Bewertung in Ökobilanzen met de Methode der ökologischen Knappheid-Ökofaktoren 1997. [Ecobalances, weighting in ecobalances with the method of ecological scarcity-ecofactors 1997]. Bern: BUWAL.

Davidson, M. D., A. F. Hof, and B. Potjer. 2002. Update schaduwprijzen. Financiële waardering van milieuemissies op basis van Nederlandse overheidsdoelen [Update shadow prices. Financial valuation of environmental emissions based upon policy targets in The Netherlands]. Delft: CE Environmental Research and Consultancy.

Dreyer, L. C., A. L. Niemann, and M. Z. Hauschild. 2003. Comparison of three different LCIA meth- ods: EDIP97, CML2001 and Eco-indicator 99Does it matter which one you choose? International Journal of Life Cycle Analysis 8(4): 191200.

Finnveden, G. 1999. Al critical review of operational valuation/weighting methods for life cycle assessment. Stockholm, Sweden: Swedish Environmental Protection Agency.

Goedkoop, M. and R. Spriensma. 2001. The EcoIndicator 99-A Damage Oriented Method for Life Cycle Impact Assessment. Methodology Report. Third edition. Amersfoort, The Netherlands: Pré Consultants B.V.

Guinée, J., ed. 2002. Handbook on life cycle assessment. Operational guide to the ISO standards. Dordrecht, The Netherlands: Kluwer Academic.

Hofstetter, P. 1998. Perspectives in life cycle impact assessment-A structured approach to combine models of the technosphere, ecosphere and valuesphere. Dordrecht, The Netherlands: Kluwer Academic Publishers.

Huppes, G., G. Warringa, M. D. Davidson, J. Kuyper, and H. A. Udo de Haes. 2003. Eco-efficient environmental policy in oil and gas production in The Netherlands. The Hague: Netherlands Oil and Gas Producers Association (NOGEPA).

Lindeijer, E. 1996. Normalisation and valuation. In Towards a methodology for life-cycle impact assessment, edited by H. A. Udo de Haes. Brussels: SETACEurope.

NAM (Nederlandse Aardolie Maatschappij). 2000. Bedrijfsmilieuplan 1999-2002. [Company environment plan.] Assen, The Netherlands: NAM.

RIVM (National Institute of Public Health and the Environment). 1999. Milieubalans 1999 [Environmental balance 1999]. Bilthoven, The Netherlands: RIVM.

RIVM. 2001. Normen en grenswaarden [Standards and limit values]. Bilthoven: RIVM.

RIVM. 2003. Milieubalans 2003 [Environmental balance 2003]. Bilthoven: RIVM.

Steen, B. 1999a. A systematic approach to environmental priority strategies in product development (EPS). Version 2000_General system characteristics. Göteborg, Sweden: Chalmers University of Technology, Environmental Systems Analysis.

Steen, B. 1999b. A systematic approach to environmental priority strategies in product development (EPS). Version 2000_Models and data of the default method. Göteborg, Sweden: Chalmers University of Technology, Environmental Systems Analysis.

Stoft, S. E. 1995. The economics of conservedenergy "supply" curves. Energy Journal 16(4): 109_ 137. 
Verdonck, P. and A. Verbruggen. 1998. The use of conservation supply curves in policy making. ENER Bulletin 22: 9-27.

VROM (Ministry of Housing, Physical Planning and the Environment). 1997. Nationaal milieubeleidsplan 3 [National environmental policy plan 3]. The Hague: VROM.

VROM. 2001. Third Netherlands national communication on climate change policies. The Hague: VROM.

Willemé, P. 2003. A statistical approach to conservation supply curves. Energy Economics 25: 553-564.

Wit, R. C. N., H. J. W. Sas, and M. D. Davidson. 1997. Schaduwprijzen. Prioriteringsmethodiek voor Milieumaatregelen (SPM) [Shadow prices. Priori- tizing method for environmental measures]. Delft: CE Environmental Research and Consultancy.

\section{About the Authors}

Evert Nieuwlaar and Walter Vermeulen are researchers at the Copernicus Institute at Utrecht University in Utrecht, The Netherlands. Geert Warringa is a former researcher at the Copernicus Institute and currently works at CE Environmental Research and Consultancy in Delft, The Netherlands. Corjan Brink is a researcher at the Netherlands Environmental Assessment Agency in Bilthoven, The Netherlands. 